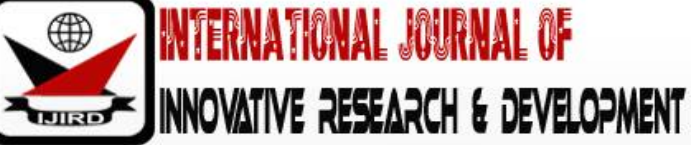

ISSN 2278 - 0211 (Online)

\section{Socio-Demographic and Cultural Determinants of Family Planning Uptake among Women of Childbearing Age in Turkana Central Sub-County, Kenya}

Daniel Mutiso Mweu
Graduate Assistant, School of Science, Turkana University College, Kenya
Dr. Catherine Gichunge
Lecturer, School of Science, Turkana University College, Kenya
Dr. Joseph Juma Nyamai
Senior Lecturer, Department of Epidemiology \& Biostatistics, School of Public Health,
Mount Kenya University, Kenya

\begin{abstract}
:
Family planning (FP) uptake is a key indicator of maternal and neonatal morbidity and mortality. Despite concerted efforts to increase the level of family planning uptake, the acceptability and coverage of FP services has remained exceptionally low in some parts of Kenya like Turkana County, thereby contributing to high unmet FP need. The purpose of the study was to determine the demographic and socio-cultural determinants of FP uptake among women of childbearing age in Turkana Central Sub-county, Kenya. The study was conducted in Turkana Central sub-county and targeted women of childbearing age. A cross sectional design was used in the study. Data was collected using structured questionnaires and interview guide. Majority of the respondents (80.8\%) were aged 15-39 years, were married (60\%), and were Christians (94.2\%). Previous use of contraceptives was the major motivator while self efficacy and affordability were reported as major enablers to FP uptake. Fear of side effects, cultural beliefs and lack of spouse support the major barriers to FP use. A significant correlation was also found between FP use and a woman's age $(r=0.309 ; p=0.001)$, religion ( $0.401 ; p=0.000)$, previous contraceptive use $(r=0.611 ; p=0.000)$ and knowledge about $F P(r=0.299 ; p=0.001)$. There was no significant correlation between FP uptake and marital status $(r=0.150 ; p=0.109)$, education level $(r=0.139$; $p=0.140)$ and employment status $(r=0.173 ; p=064)$. The study underscores the need for targeted health education interventions to women of reproductive age in areas with low family planning through provision of accurate information on available family planning options and their benefits.
\end{abstract}

Keywords: Family planning, demographic factors, socio-cultural factors, childbearing age

\section{Background}

Family planning is an essential public health intervention because it confers health and socioeconomic benefits for individuals, families, and the entire population. FP is particularly beneficial to women and children as it helps in preventing pregnancy-related morbidity and mortality, reducing infant mortality and unsafe abortions, reducing sexual transmission of human immunodeficiency virus (HIV) transmission and sexually transmitted infections (STI), and preventing mother-to-child HIV/ AIDS transmission (MCHT) among other benefits (World Health Organization, 2018). Access to family planning for women of reproductive age is also critical towards attaining the United Nation's Sustainable Development Goal of securing health and well-being for all and attaining universal health coverage.

Despite the documented benefits of family planning, the unmet need for family planning remains exceptionally high. According to WHO (2018), about 214 million women of reproductive age in developing nations who want to avoid pregnancy are not using a modern contraceptive method due to various reasons (WHO, 2018). In Africa, 24 percent of women of reproductive age have an unmet need for modern contraception (WHO, 2018). This inequity is fuelled by both a growing population, shortage of family planning services, and persistent cultural beliefs and practices among other factors (Malalu, 2014; WHO, 2018). Lack of access to family planning services by women willing to avoid or delay pregnancy may lead to increased maternal and child deaths besides other negative socio-economic outcomes.

Contraceptive use has increased in many parts of the world, especially in Asia and Latin America, but continues to be low in sub-Saharan Africa. In Kenya, contraceptive uptake has increased from 53 percent in 2014 to 59 percent in 2017, a six-point increment over the last three years (Malalu, 2014). According to the Kenya Demographic and Health Survey (KDHS) [2015], Turkana County has the second lowest rate of contraceptive uptake in Kenya, with only $10.4 \%$ against the national average of $53 \%$. Besides, the county has one of the highest fertility index of 6.9 compared to the country's fertility 
index average of 3.9 (KDHS, 2015). One of the key milestones in reducing the unmet need for family planning is by identifying the factors that motivate reproductive woman to use or hinder them from using contraceptives. A systematic review by Ackierson and Zielinski (2017) suggested that demographic, social, and psychological characteristics motivate a person to use or not to use family planning services. Age has been cited as one of the determining factors for contraceptive use (Johnson, Pion \& Jennings, 2015; Sileo, 2014). Some studies have reported low uptake of FP among older women, which has been linked to several reasons including low acceptability of contraceptive, and less need for use among older women as well as traditional beliefs about family size (Malalu, 2014; Ackierson Zielinski, 2017; Rodríguez, Say, and Temmerman, 2014).

Most previous studies do not clearly explain the correlation between current family planning uptake and the socio-cultural factors among women of childbearing age, particularly in areas with low FP uptake. Qualitative studies in Kenya show that while contraceptives are given free in many government facilities, there are some indirect costs such as laboratory tests, transport to the clinic, childcare, and loss of work hours, which may hinder women from accessing family planning services (Malalu, 2014; Kisia, Koskei, Too and Chirchir, 2014; Ochako, Mbondo, and Aloo, 2015). This underscores the need to investigate the association between FP use and various factors in order to establish which among them are strongly associated with contraceptive use. Against this backdrop, this study sought to address the existing research gap by examining the demographic and socio-cultural factors which influence women of childbearing age or hinder them from using family planning in an area which has not been covered by previous studies and has a low contraceptive prevalence rate.

\section{Materials and Methods}

The study adopted a cross sectional mixed methods design using both quantitative and qualitative data. The qualitative data was used to supplement the findings from the quantitative data. The study was conducted in Turkana Central Sub-county, Turkana County, Kenya. The study targeted women of childbearing age (15-49 years) in the study area. Simple random sampling approach was used to select the first household in each sampling unit followed by systematic random sampling where every $10^{\text {th }}$ household was selected. The dependent variable in the study was family planning uptake. The independent variables were socio-demographic characteristics, motivating factors, enabling factors and barriers to family planning. Family planning uptake was defined as the use of modern family planning methods by a woman of childbearing age. Socio-demographic characteristics were defined as factors such as a woman's age, marital status, education level, religion, and employment status, which could predispose a woman to use family planning services. The measurement scale was continuous. Motivating factors were defined as factors that increase the likelihood of a woman of reproductive age to use family planning like previous categorical contraceptive use, knowledge, and desire to have children. The measurement scale was categorical, coded 0 for 'no' and 1 for 'yes'. Enabling factors were defined as factors that make it possible or easier for a woman of reproductive age to use family planning like self efficacy, affordability, and access to FP services. They were measured using a Likert Scale. Barriers were defined as socio-cultural factors which hinder women of childbearing age from using family planning services such as cultural practices, beliefs and traditions as reported by the respondents.

Quantitative data was collected using structured questionnaires while qualitative data was collected using interview guide. The filled questionnaires were checked for completeness and coded to make it easier to analyze. Statistical Package for Social Sciences (SPSS) version 20.0 was used to aid in the analysis. For categorical variables, frequencies were generated while cross tabulations were done to establish the relationship among variables. Further, bivariate analyses of various variables were done to determine correlation between variables under investigation. Before data collection, an ethical clearance letter was provided by Mount Kenya University Ethical Review Committee (Ref: MKU/ ERC/ 0472), while a research permit was obtained from the National Commission for Science, Technology and Innovation (NACOSTI) [Ref: NACOSTI/ P/ 17/ 53095/ 18799].

\section{Results}

\subsection{Socio-Demographic Characteristics}

The results of demographic characteristics are presented in Table 1. Majority of the respondents (80.8\%) were aged 15 -39 years while only $19.2 \%$ were aged $40-49$ years. $60 \%$ were married, while $4.2 \%$ were separated/ widowed or divorced. Majority were Christians (94.2\%). 52.1\% had attained secondary education level while $21 \%$ had attained primary education or no education at all. 59.6\% were self employed, while $16.0 \%$ had no employment.

\subsection{Motivators and Enablers of Family Planning Uptake}

The results of motivating factors of family planning uptake are presented in Table 2 . An overwhelming majority (95.0\%) were aware of one or more family planning methods. Majority (92.5\%) had child (ren). $62.8 \%$ desired to have a child (ren) in future while $37.2 \%$ did not desire to have more children. As indicated in Table 3 for enablers of family planning uptake, $23.3 \%$ strongly agreed while $10.8 \%$ (13) strongly disagreed that ability to make informed choices regarding family planning (self efficacy) encouraged them to use family planning services. $35.3 \%$ of the respondents strongly agreed whereas 4.2\% strongly disagreed that affordability was an enabling factor to using FP services. 52.9\% strongly agreed while $5.0 \%$ strongly disagreed that availability and access to family planning services encouraged them to use FP services. 


\subsection{Socio-Cultural Barriers to Family Planning Uptake}

The major reported barriers include negative cultural practices and myths about contraceptives, disapproval of the spouse and fear of side effects after contraceptive use. It was revealed that some women fail to take contraceptives because of rumors in the community that the family planning can cause some health problems. One participant responded; "There are many rumors going on that when a woman takes pills, they build up inside the body and cause fibroids and uterine cancer, and when they think about that, they fear contraceptives". Another respondent reported that some women refuse to take contraceptives because of myths that they will become barren; "Some women fear taking contraceptives because they have heard rumors that if a woman takes family planning, she will never be able to conceive anymore because her fallopian tubes will be blocked and this discourages them from taking contraceptives".

It emerged that some women fail to take family planning because they were re not allowed to talk about sexuality issues as that is considered as a taboo. Others failed to use contraceptives because having more children has a certain cultural value among the community members as one respondent reported; "There are those women who refuse to go for contraceptives because they claim that they will stop bearing children". This is a big problem especially for those with a small family like one kid; they usually say, "what if I stop, that means I will only have one kid. This makes them refuse". It was reported that some men were reluctant to allow their spouses to use contraceptives. As one respondent reported; "there is also a belief that if a woman has only one child and s/ he dies, there is going to be nobody to inherit the family name. The fear of side effects of the contraceptives was also cited as a major hindrance to family planning use. One respondent reported; "some women say that they don't want to suffer from headaches everyday or become very thin due to the pills".

\subsection{Association between Independent Variables and Family Planning Uptake}

The results of bivariate analysis using Pearson Correlation Coefficient to determine the association between the independent variables and family planning utilization are presented in Table 4 . The results indicate that a woman's age $(\mathrm{r}=0.309 ; \mathrm{p}=0.001)$ and religion $(\mathrm{r}=0.401 ; \mathrm{p}=0.000)$ were the major demographic factors associated with FP uptake. Knowledge of family planning $(\mathrm{r}=0.299 ; \mathrm{p}=0.001)$, previous FP use $(\mathrm{r}=0.611 ; \mathrm{p}=0.000)$, gravidity (having a child (ren) $(\mathrm{r}=0.204 ; \mathrm{p}=0.028)$, and having children at desired age $(0.454 ; \mathrm{p}=0.000)$ were the motivators which had significant association with uptake of family planning services. Affordability of FP services $(r=0.225 ; p=0.022)$ was the major enabler which was significantly associated with uptake of family planning services. There was no significant correlation between family planning use and a woman's marital status $(r=0.150 ; p=0.109)$, education level $(r=0.139 ; p=0.140)$ and employment status $(r=0.173 ; p=.064)$.

\section{Discussion and Conclusion}

The study examined the socio-demographic and cultural determinants of family planning uptake among women of childbearing age. The findings on influence of knowledge of FP on uptake are supported by other studies which assert that awareness of contraceptive methods is an indicator of the level of FP acceptance and consequent use (Nabi, 2015). In areas where people have more exposure to FP information through the mass media and other channels, family planning uptake is highly accepted and utilized (Bolarinwa, 2015). The study findings imply that lack of correct information on family planning methods can be a barrier to family planning uptake. Age and number of children were significantly associated with family planning use. Some studies have reported that women of reproductive age were motivated to use contraceptives in order to limit the number of children and space their births, which encourages them to access FP services (Davidson et al, 2016). The study revealed that a significant proportion of the women were not using family planning services as they desired to have more children in future. These findings are consistent with those by Shafii et al (2014) which pointed out that having adequate numbers of children and above all, avoiding being childless have a significant influence on the use of contraceptives. This may account for low current FP use among the respondents in this study.

Marital status and education level were not significantly correlated with current use of FP among the respondents. These findings are not in agreement with those of a study carried out across 24 countries in Sub-Saharan Africa which indicated that women with higher education levels were more likely to use FP services compared to their less educated counterparts (Davidson et al, 2016). The positive correlation between a woman's education level and family planning use can be explained in several ways. Key among these includes positive effect of education on women empowerment and ability to make informed choices (Shafii et al, 2014). Evidence from this study suggested that ability to make informed choices (self efficacy) about FP and awareness of FP benefits, affordability of the services, and previous FP use were the major enabling factors to FP use among the respondents. Self-efficacy and previous FP use were found to be the strongest enabling factors for FP use among the respondents. These findings are in agreement with those reported by other studies which reported that information awareness and decision-making power had influence over choices on health (Eliason, 2013; Kiura, 2014).

Previous use of contraceptive was found to be a key motivator of FP use by women of reproductive age. These findings are corroborated by the findings in a study by Mosha, Ruben and Kakoko (2013), which established that women who reported prior contraceptive use were more than 11 times more likely to utilize FP services compared to those who did not report prior contraceptives use. Past behaviour has been found to be a strong predictor of future behavior, possibly due to habit forming following repeated performance (Malalu, 2014; Davidson et al, 2016). Previous FP may also exert its effect on present use by increasing self efficacy (Malalu, 2014).

The study identified several reasons which hinder women from using family planning methods. The most common reasons cited were lack of spouse (husband) consent, religious principles, fear and concerns of side effects. These reasons have also been reported in other studies. In Pakistan, supposed side effects like abdominal pains, excessive bleeding, and 
concerns about infertility were reported as the major reasons why women failed to use contraceptive methods (Tabassum, 2016). The study findings revealed that the decision to use or not to use family planning methods did not entirely rest with women but was partially influenced by the husbands. A study by Adelekan, Omoregie, and Edoni (2014) in Nigeria reported that women who used contraceptives without the consent of the husband were branded as being promiscuous. Similar results were reported in a nationwide study in Kenya which revealed that most men expressed concerns about family planning that it led to decline in sexual desire, birth defects, or in some cases discomfort during sexual intercourse, hence, men did not fully support the use of modern family planning methods (Ochako, et al., 2015). Furthermore, evidence from Uganda (Kabagenyi, 2014) and Nigeria (Gueye, Speizer, and Corroon, 2015) revealed that spouse opposition was the major reason why women did not use modern contraceptives.

The study had certain limitations. First, there was a likelihood of inaccuracy in the reporting of the current FP use since discussions of reproductive health and sexuality issues is regarded as taboo in some cultural practices (Davidson et al, 2016, Eliason, 2013). This limitation was likely to be more pronounced among participants with low literacy levels (Wafula, Obare \& Bellows, 2014). Second, there was a possibility of losing some cultural nuances during the interpretation of the questions and transcription. This study concluded that a woman's age, religion, having one or more children, desire to have a child (ren) at desired age and knowledge about the various FP methods were the major socio-demographic determinants of family planning uptake. Fear of side effects, cultural beliefs and lack of support or consent from the husband were the key barriers to family planning uptake among women of reproductive age. The study suggests the need for women of reproductive age to be adequately informed on FP choices and their health benefits, especially in the remote areas so as to demystify some of the myths and cultural beliefs surrounding family planning.

\section{Acknowledgement}

Our sincere gratitude goes to the respondents for cooperating and providing valuable information for this study. We also thank the Sub-county Commissioner, Turkana Central Sub-county for granting the permission to collect data.

\begin{tabular}{|c|c|c|}
\hline Variable & (N) & $\mathbf{\%}$ \\
\hline Age Group (years) & & \\
\hline 15-19 years & 15 & $12.5 \%$ \\
\hline 20 - 29 years & 35 & $32.5 \%$ \\
\hline 30 - 39 years & 43 & $35.8 \%$ \\
\hline 40 - 49 years & 23 & $19.2 \%$ \\
\hline Marital status & & \\
\hline Single & 43 & $35.8 \%$ \\
\hline Married & 72 & $60.0 \%$ \\
\hline Separated/ Divorced/Widowed & 5 & $4.2 \%$ \\
\hline Educational level & 25 & $21.0 \%$ \\
\hline Primary level and below & 62 & $52.1 \%$ \\
\hline Secondary level & 33 & $26.9 \%$ \\
\hline University/ college level and above & & \\
\hline Religion & 113 & $94.2 \%$ \\
\hline Christian & 7 & $5.8 \%$ \\
\hline Muslim/ others & 19 & \\
\hline Employment status & 71 & $59.0 \%$ \\
\hline Unemployed/ retired & 29 & $24.4 \%$ \\
\hline Self Employed & &
\end{tabular}

Table 1: Demographic Characteristics

\begin{tabular}{|c|c|c|c|c|c|}
\hline \multicolumn{2}{|c|}{ Variable } & $\mathbf{N}$ & $\mathbf{0}$ & \multicolumn{2}{c|}{ Current FP Use } \\
\cline { 4 - 6 } & & & Yes: \% (N) & No: \% (N) \\
\hline $\begin{array}{c}\text { Knowledge/ awareness } \\
\text { of FP Methods }\end{array}$ & Yes & 114 & $95.0 \%$ & $75 \%(85)$ & $25 \%(29)$ \\
\cline { 2 - 6 } & No & 6 & $5.0 \%$ & $33 \%(2)$ & $67 \%(4)$ \\
\hline Previous FP use & Yes & 103 & $85.8 \%$ & $83 \%(85)$ & $17 \%(18)$ \\
\cline { 2 - 6 } & No & 17 & $14.2 \%$ & $12 \%(2)$ & $88 \%(15)$ \\
\hline $\begin{array}{c}\text { Gravida (have children } \\
\text { or not) }\end{array}$ & Yes & 111 & $92.5 \%$ & $75 \%(83)$ & $25 \%(28)$ \\
\cline { 2 - 6 } & No & 9 & $7.5 \%$ & $33 \%(3)$ & $67 \%(6)$ \\
\hline $\begin{array}{c}\text { Desire to have more } \\
\text { children }\end{array}$ & Yes & 74 & $62.8 \%$ & $89 \%(66)$ & $11 \%(8)$ \\
\cline { 2 - 6 } & No & 46 & $37.2 \%$ & $52 \%(24)$ & $48 \%(22)$ \\
\hline
\end{tabular}

Table 2: Motivators of Family Planning Uptake 


\begin{tabular}{|c|c|c|c|c|c|c|}
\hline & Item & $\begin{array}{c}\text { Strongly } \\
\text { Disagree } \\
\mathbf{\%} \mathbf{( N )}\end{array}$ & $\begin{array}{c}\text { Disagree } \\
\mathbf{\%}(\mathbf{N})\end{array}$ & $\begin{array}{c}\text { Neither Agree Nor } \\
\text { Disagree } \\
\mathbf{\%}(\mathbf{N})\end{array}$ & $\begin{array}{c}\text { Agree } \\
\mathbf{\%}(\mathbf{N})\end{array}$ & $\begin{array}{c}\text { Strongly } \\
\text { Agree } \\
\mathbf{\%}(\mathbf{N})\end{array}$ \\
\hline 1. & $\begin{array}{c}\text { Ability to make informed } \\
\text { choices on FP (self efficacy) }\end{array}$ & $\begin{array}{c}10.8 \% \\
(13)\end{array}$ & $5.8 \%(7)$ & $29.2 \%(35)$ & $30.8 \%$ & $23.3 \%(28)$ \\
& & & & & \\
\hline 2. & Affordability of FP services & $\begin{array}{c}4.2 \% \\
(5)\end{array}$ & $7.6 \%(9)$ & $21.8 \%(26)$ & $\begin{array}{c}21.8 \% \\
(26)\end{array}$ & $31.1 \%(37)$ \\
\hline 3. & $\begin{array}{c}\text { Access/ availability of FP } \\
\text { services }\end{array}$ & $\begin{array}{c}5 \% \\
(6)\end{array}$ & $4.2 \%(5)$ & $10.9 \%(13)$ & $\begin{array}{c}26.9 \% \\
(32)\end{array}$ & $52.9 \%(63)$ \\
\hline
\end{tabular}

Table 3: Enablers of Family Planning Uptake

\begin{tabular}{|c|c|c|c|}
\hline & Independent variables & $\begin{array}{c}\text { Pearson Correlation } \\
\text { Coefficient (r) }\end{array}$ & P-value \\
\hline 1. & Age & $0.309^{* *}$ & 0.001 \\
\hline 2. & Marital status & 0.150 & 0.109 \\
\hline 3. & Religion & $0.401^{* *}$ & 0.000 \\
\hline 4. & Education level & 0.139 & 0.140 \\
\hline 5. & Employment status & 0.173 & 0.064 \\
\hline 6. & Knowledge/ awareness of FP & $0.299^{* *}$ & 0.001 \\
\hline 7. & Previous FP use & $0.611^{* *}$ & 0.000 \\
\hline 8. & Gravidity (having a child(ren) & $0.204^{*}$ & 0.028 \\
\hline 9. & To have a child(ren) at desired age & $0.454^{* *}$ & 0.000 \\
\hline 10. & Affordability/access to FP services & $0.225^{*}$ & 0.022 \\
\hline
\end{tabular}

Table 4: Association between Independent Variables and FP Uptake

\section{References}

i. Ackierson, K. \& Zielinski, R. (2017). Factors influencing use of family planning in women living in crisis affected areas of Sub-Saharan Africa: A review of the literature. Midwifery, 5 435-60.

ii. Adelekan, A., Omoregie, P., \& Edoni, E. (2014). Male Involvement in Family Planning: Challenges and Way Forward. International Journal of Population Research, Article ID 416457.

iii. Bolarinwa, O.A. (2015). Principles and methods of validity and reliability testing of questionnaires used in Questionnaires used in social and health science researches. Nigerian Postgraduate Medical Journal, 22, 195-201.

iv. Davidson, A.S., Fabiyi, C., Demissie, S., Getachew, H. \& Gilliam, M.L. (2016). Is LARC for everyone? A qualitative study of socio-cultural perceptions of family planning and contraception among refugees in Ethiopia. Maternal and Child Health Journal, 1-7.

v. Eliason, S. (2013). Factors influencing the intention of women in rural Ghana to adopt postpartum family planning. Reproductive Health, 10(1).

vi. Gueye, A., Speizer, I.S. \& Corroon, M. (2015). Belief in family planning myths at the individual and community levels and modern contraceptive use in urban Africa. International Perspectives on Sexual Reproductive Health, 41(4): 191-199.

vii. Johnson, S., Pion, C. \& Jennings, V. (2015). Current methods and attitudes of women towards contraception in Europe and America. Reproductive Health, 10, 7.

viii. Kabagenyi, A. (2014). Barriers to male involvement in contraceptive uptake and reproductive health services: a qualitative study of men and women's perceptions in two rural districts in Uganda. Reproductive Health, 11, 21.

ix. Kenya Demographic and Health Survey (KDHS). (2014). Key indicators. Nairobi: Kenya.

x. Kisia, P.M., Koskei, A., Too, R. \& Chirchir, A. (2014). Determinants of Use of Modern Family Planning Methods: A Case of Baringo North District, Kenya. Science Journal of Public Health, 2 (5), 424-430.

xi. Kiura, A.W. (2014). Constrained agency on contraceptive use among Somali refugee women in the Kakuma Refugee Camp in Kenya. Gender, Technology and Development, 18, 147-161.

xii. Malalu, P.K. (2014). Determinants of use of modern family planning methods: A case of Baringo North District, Kenya. Science Journal of Public Health, 2 (5), 424-430.

xiii. Ministry of Health. (2017). Family planning services. Government of Kenya.

xiv. Mosha, I., Ruben, R. \& Kakoko, D. (2013). Family planning decisions, perceptions and gender dynamics among couples in Mwanza, Tanzania: a qualitative study. BMC Public Health, 13, 523.

xv. Nabi, R.L. (2015). Emotional flow in persuasive health messages. Health Communication, 30, 114-124.

xvi. Ochako, R., Mbondo, M. \& Aloo, S. (2015). Barriers to modern contraceptive methods uptake among young women in Kenya: a qualitative study. BMC Public Health, 15, 118.

xvii. Ochako, R., Mbondo, M., Aloo, S., Kaimenyi, S., Thompson, R., Temmerman, M. et al (2015). Barriers to modern contraceptive methods uptake among young women in Kenya: a qualitative study. BMC Public Health, 15(118): 19.

xviii. Rodríguez, I., Say, L. \& Temmerman, M. (2014). Family planning versus contraception: what's in a name? The Lancet Global Health, 2(3), 131-2. 
xix. Shafii, T., Hoopes, A.J., Benson, S.K., Ko, L.K., Morrison, D.M., Buesseler, H.M. \& Holmes, K.K. (2014). How does the provider-patient interaction shape the experience of sexual health communication? A qualitative study of adolescents and young adult (S17-S17). Journal of Adolescent Health, 54.

xx. Sileo, K.M. (2014). Determinants of family planning service uptake and use of contraceptives among postpartum women in rural Uganda. Unpublished Master's Thesis.

xxi. Tabassum, A. (2016). Perceptions of rural women about contraceptive usage in district Khushab, Punjab. JPMA, 66, 1577-81.

xxii. Wafula, S., Obare, F., Bellows, B. (2014). Evaluating the impact of promoting long acting and permanent methods of contraceptives on utilization: results from a quasi experimental study in Kenya. In: Population Association of America 2014.

xxiii. Warren, C., Abuya, T. \& Askey, I. (2013). Family planning practices and pregnancy intentions among HIV-positive and HIV-negative postpartum women in Swaziland: A cross sectional survey. BMC Pregnancy and Childbirth, 13, 150.

xxiv. World Health Organization (2018). Family planning/contraception. http://www.who.int/ news-room/factsheets/ detail/ family-planning-contraception. 